\title{
Bibliometric analysis of global research output on antimicrobial resistance in the environment (2000-2019)
}

\author{
Waleed M. Sweileh ${ }^{*}$ (D) and Ahmad Moh'd Mansour ${ }^{2}$
}

\begin{abstract}
Background: Antimicrobial resistance (AMR) is a global health threat that requires a "One Health" approach. Of the One Health triad, the environmental component is the most dynamic and most neglected. Therefore, the objective of the current study was to assess and analyze global research activity on AMR in the environment.

Methods: This was a bibliometric descriptive study of publications on AMR in the environment. Publications were retrieved using SciVerse Scopus for the study period from 2000 to 2019. The search query was developed using terms and phrases related to the topic. The retrieved publications were analyzed for specific bibliometric indicators including annual growth, citation analysis, key players, research output for each world regions, research themes, and occurrences of different drug classes of antimicrobials. Visualization maps including research collaboration were created using VOSviewer program. The Hirsch $(h)$ index was used to assess scientific impact.

Results: There were 2611 research articles based on the implemented research query. The retrieved documents had an average of 22 citations per document and an $h$-index of 122 . The annual number of publications showed a steep increase from 2011 to 2019. The major research themes in the field were (1) dissemination and abundance of antibiotic-resistant genes and (2) detection of bacterial strains or antibiotic residues in various environmental isolates. The bulk of the retrieved articles ( $n=899 ; 34.4 \%)$ originated from the European region. China led with 598 (22.9\%) documents. Four of the top 10 active institutions were in China. The top 10 active countries had relatively inadequate international research collaboration. The most commonly encountered antibiotic drug classes in the retrieved articles were penicillin/cephalosporin ( $n=1152$ occurrences). The most frequently encountered pathogen in the retrieved publications was E. coli $(n=666)$. The Science of the Total Environment journal was the most prolific journal with 139 (5.3\%) publications.
\end{abstract}

Conclusion: Scientific literature on the AMR in the environment has witnessed a steep growth lately with a leading role of China and Chinese institutions. Data on AMR in the environment need to be collected from all world regions including the Eastern Mediterranean and African regions through research collaboration and funding of research in this field.

Keywords: Antimicrobial resistance, Environment, Research activity, One health

\footnotetext{
* Correspondence: waleedsweileh@yahoo.com

'Department of Physiology, Pharmacology/Toxicology, College of Medicine

and Health Sciences, An-Najah National University, Nablus, Palestine

Full list of author information is available at the end of the article
}

(c) The Author(s). 2020 Open Access This article is licensed under a Creative Commons Attribution 4.0 International License, which permits use, sharing, adaptation, distribution and reproduction in any medium or format, as long as you give appropriate credit to the original author(s) and the source, provide a link to the Creative Commons licence, and indicate if changes were made. The images or other third party material in this article are included in the article's Creative Commons licence, unless indicated otherwise in a credit line to the material. If material is not included in the article's Creative Commons licence and your intended use is not permitted by statutory regulation or exceeds the permitted use, you will need to obtain permission directly from the copyright holder. To view a copy of this licence, visit http://creativecommons.org/licenses/by/4.0/. 


\section{Background}

Antimicrobial resistance (AMR) is a global health threat [1] that requires a "One Health" approach [2-4]. The "One Health" approach recognizes that the health of people is closely connected to the health of animals and the environment [5]. The "One Health" approach has been adopted by the United Nation (UN) in the fight against AMR and in the roadmap to achieve the third goal in Sustainable Development Goals 2030 (SDGs) about health and well-being $[6,7]$. Therefore, a holistic approach is required to confront global public health problems, such as AMR, that is present in humans, animals, and the environment $[8,9]$. Of the One Health triad, the environment component is the most dynamic and most neglected [10].

The AMR is the consequence of multiple factors related to inappropriate and overuse of antimicrobial agents in humans, animals, food chain, and the exposure of the environment to antimicrobial agents [11]. Antimicrobials end up in the environment through industrial, pharmaceutical, and hospital effluents as well as human and animal wastes [12]. For example, antimicrobial agents are found in large quantities in aquatic environments, sewage and wastewater treatment plants $[12,13]$. There are several routes for transmission of antibioticresistant bacteria from humans and animals to the environment, and since all environmental compartments are connected, these resistant bacteria can be transmitted back to humans through water, animal-producing food, vegetables, fruits, and other edible agricultural products [14-16].

Assessment of research activity on AMR in the environment is used to achieve several goals: (1) evaluate the progress and growth of literature dedicated to discuss AMR in a "One Health" approach; (2) help draw a global map on regions with a poor contribution to the One Health approach in combating AMR and therefore be subject to encouragement and collaboration from various international organizations and academic/research institutions which strengthens the collaborative and multi-sectoral approach recommended by the "One Health"; (3) help identify prominent research/academic institutions involved in this field and direct international funding to such institutions, (4) help developing strategic national decisions concerning national action plans in combating AMR; (5) help microbiologists, pharmacologists, and clinicians understand what pathogens and antimicrobials that are being cycled at the human-animalenvironment interface; and (6) establish the role of various scientific subject areas in the published literature on AMR and the environment.

Research activity is usually evaluated and assessed using bibliometric analysis, which is defined as the quantitative analysis of science using statistical methods and mapping techniques. Bibliometric analysis is different from systematic reviews and scoping reviews. In a bibliometric analysis, documents are retrieved using a single database and analyzed quantitatively and qualitatively for specific bibliometric indicators [17, 18]. Bibliometric analysis is not inclusive of grey literature. In systematic reviews, a research question is answered using a limited number of publications selected from different databases, including grey literature. In systematic reviews, but not in bibliometric analysis, the initially retrieved documents include a large percentage of duplicate documents that are filtered using certain selection methods. In systematic reviews, researchers might follow up with the analysis and carry out meta-analysis, which is not the case in the bibliometric analysis $[19,20]$. For scoping reviews, it is defined as a preliminary assessment of potential size and scope of available research literature, usually including ongoing research, and aims to identify nature and extent of research evidence [21, 22]. Bibliometric studies on various aspects of AMR such as carbapenem resistance, antimalarial drug resistance, antituberculosis drug resistance, uropathogen resistance, and several others have been published [23-27]. However, no bibliometric studies have been published on AMR in the environment. Therefore, the current study was undertaken to assess and analyze the global research activity on AMR in the environment.

\section{Methods}

\section{Database selection}

In the current study, Scopus database was used as a tool to retrieve the relevant documents. Several advantages of Scopus make it suitable for such studies. First, Scopus provides basic and advanced search options and allows for the use of different Boolean operators, which allow for the development of comprehensive search query. Second, Scopus has many analytic functions such as citation and subject analysis. Third, quantitative analysis regarding active key players can be extracted from Scopus directly. Fourth, Scopus allows simple export of Scopus data to Microsoft Excel or any other program such as VOSviewer for further analysis and mapping. Fifth, Scopus is superior to Pubmed because Pubmed is 100\% inclusive in Scopus. Sixth, Scopus is larger and has more non-English scientific journals than Web of Science [28]. This is important because in the current study no language restriction was imposed. All documents published in Scopus must have an English title and abstract, which enables researchers to confirm the content of nonEnglish documents through title/abstract content.

\section{Search strategy}

The key step in bibliometric studies is the development of a comprehensive search query with a high tested 
validity to ensure accurate analysis and outcome. The search query in the current study was developed after reviewing both scientific publications and grey literature on the topic to develop a bank of relevant keywords to be used in the search query [29-31]. In the current study, the search query was based on two search scenarios joined by the Boolean operator "AND". The first scenario was dedicated to retrieve documents on AMR: "antibiotic resistan" or "antimicrobial resistan" or "antibacterial resistan" "while the second scenario was dedicated for documents related to the environment (e.g. water or soil or waste or sludge or aquatic or manure or sewage or effluent or "wild animal"" or "f"ecal contamination" or vegetable* or fruit* or river). The asterisk and quotation marks were used in the research query to increase comprehensiveness and accuracy. Both scenarios were then combined. The flow diagram of study selection is shown in Supplementary material 1 while the keywords used in the search strategy are shown in Supplementary material 2 . The PRISMA checklist is shown in Supplementary material 3.

\section{Refining the retrieved documents}

The retrieved documents were limited to journal research articles only. Therefore, books, notes, letters, editorials, and errata were excluded. The purpose of this step was to focus on original research rather than scientific publications in the form of commentaries, notes, and others. The study period was limited from 2000 to 2019. The choice of the study period was based on the understanding that AMR became internationally a serious health problem in the past two decades. Furthermore, the initial assessment of the literature showed that there were few publications on AMR from the perspective of the environment before the year 2000. No language restriction was imposed on the retrieved literature.

\section{Validation of the search strategy}

In the current study, the development of the search query was continuously fine-tuned until the top 200 cited documents in the retrieved literature were free of any false-positive results. Furthermore, the search query was tested for missing data (false-negative) by adopting a previously published method which relies on the correlation between the retrieved research output for active authors and their actual research output in this field [27].

\section{Data export and analysis}

Retrieved data were exported from Scopus to Microsoft Excel for analysis and table presentation. Graphics were created using Statistical Package for Social Sciences (SPSS, version 21). Geographical distribution of publications was carried out using the WHO geographical classification: the region of the Americas; the European region, the Eastern Mediterranean region, the African region, the South-Eastern Asia region, and Western Pacific region). Visualization maps were created using VOSviewer program [32]. International research collaboration among active countries was assessed using the "link strength" indicator extracted from visualization maps. The link strength is a measure of the strength of research collaboration between any two countries. The link strength is proportional to the thickness of connecting lines between countries. The higher the value of link strength, the thickness of the connecting line, the stronger the research collaboration [33].

The scientific impact of publications from different countries can be compared using the normalized citation value of the published documents from each country. The normalized citation value was obtained from the network visualization maps created by VOSviewer. The normalized citation of the research output of any specific country is proportional to the node size for that country in the normalized citation visualization map. The larger the node size of the country, the higher the scientific map of its research output [33]. The Hirschindex ( $h$-index) was used to measure the scientific impact of authors, institutions, countries, and a body of literature. The $h$-index is defined as the maximum value of $\mathrm{h}$ such that the given author/journal has published $\mathrm{h}$ papers that have each been cited at least $h$ times [34]. The $h$-index is proportional to research productivity and the number of citations.

\section{Bibliometric indicators}

In the current study, the following bibliometric indicators were presented: (1) volume and growth of publications on AMR in the environment over the past two decades; (2) research output from different world regions; (3) subject areas of literature on AMR in the environment; (4) most active countries, institutions, journals, and funding agencies involved in publishing scientific articles on AMR in the environment; and (5) the antimicrobial drug classes and pathogens mostly encountered in the retrieved literature.

\section{Results}

\section{Characteristics of the retrieved publications}

The search query implemented in Scopus database retrieved 2611 research articles. The majority of the retrieved articles $(n=2425 ; 92.9 \%)$ were research articles, review articles $(n=164 ; 6.3 \%)$, and conference papers $(n=22 ; 0.8 \%)$. The language in the majority of the retrieved articles was English $(n=2470 ; 94.6 \%)$ followed by Chinese $(n=80 ; 3.1 \%)$ and Spanish $(n=10 ; 0.4 \%)$. Other less commonly encountered languages included 
Portuguese, German, French, Korean, and Russian. Less than one-third of the retrieved research articles $(n=849$; $32.5 \%)$ were available as open access for readers.

\section{Subject areas of the retrieved documents}

The retrieved articles belonged to the following subject areas: environmental sciences $(n=1234 ; 47.3 \%)$, immunology/microbiology $(n=799 ; 30.6 \%)$, medicine $(n=652$; $25.0 \%)$, agricultural and biological sciences $(n=555$; $21.3 \%)$, biochemistry/genetics/molecular biology $(n=$ $486 ; 18.6 \%)$, and pharmacology/toxicology $(n=231$; $8.8 \%)$.

\section{Annual growth of publications}

The graph for annual growth of publications showed two phases: a slow phase from 2000 to 2010 and a steep phase from 2011 to 2019. Figure 1 is a representation of the annual growth of publications where the blue line represented the growth of worldwide publications on AMR while the green dashed line represented the annual growth of publications on AMR in the environment. The graph was created on a dual Y-axis to compare the two lines. The figure showed that the gap between the two lines is narrowing with time indicative of greater worldwide interest in the role of environment in the propagation of AMR. In the year 2000, publications on
AMR in the environment constituted $2.6 \%$ of the overall publications on AMR. However, in 2019, publications on AMR in the environment constituted $11.0 \%$ of the overall publications on AMR. The search query on AMR alone found 38,639 publications and therefore the research on the AMR in the environment constituted $6.7 \%$ $(n=2611)$ of the overall AMR literature.

\section{Research themes}

Visualization of terms in the titles/abstracts and having minimum occurrences of 50 times showed that there were two major research themes in the field (Fig. 2). The first theme (green) represented research on the dissemination and abundance of antibiotic-resistant genes in the environment while the second theme (red) represented research on detection of bacterial strains or antibiotics in environmental isolates.

\section{Antimicrobials and pathogens}

Analysis of indexed keyword occurrences showed that the most commonly encountered antibiotic drug classes were penicillin/cephalosporin $(n=1152$ occurrences) followed by aminoglycosides $(n=1058)$ (Table 1$)$. Analysis also showed that the most commonly encountered pathogens were E. coli $(n=666)$, Pseudomonas aeruginosa $(n=172), \quad$ Staphylococcus aureus $(n=154)$,

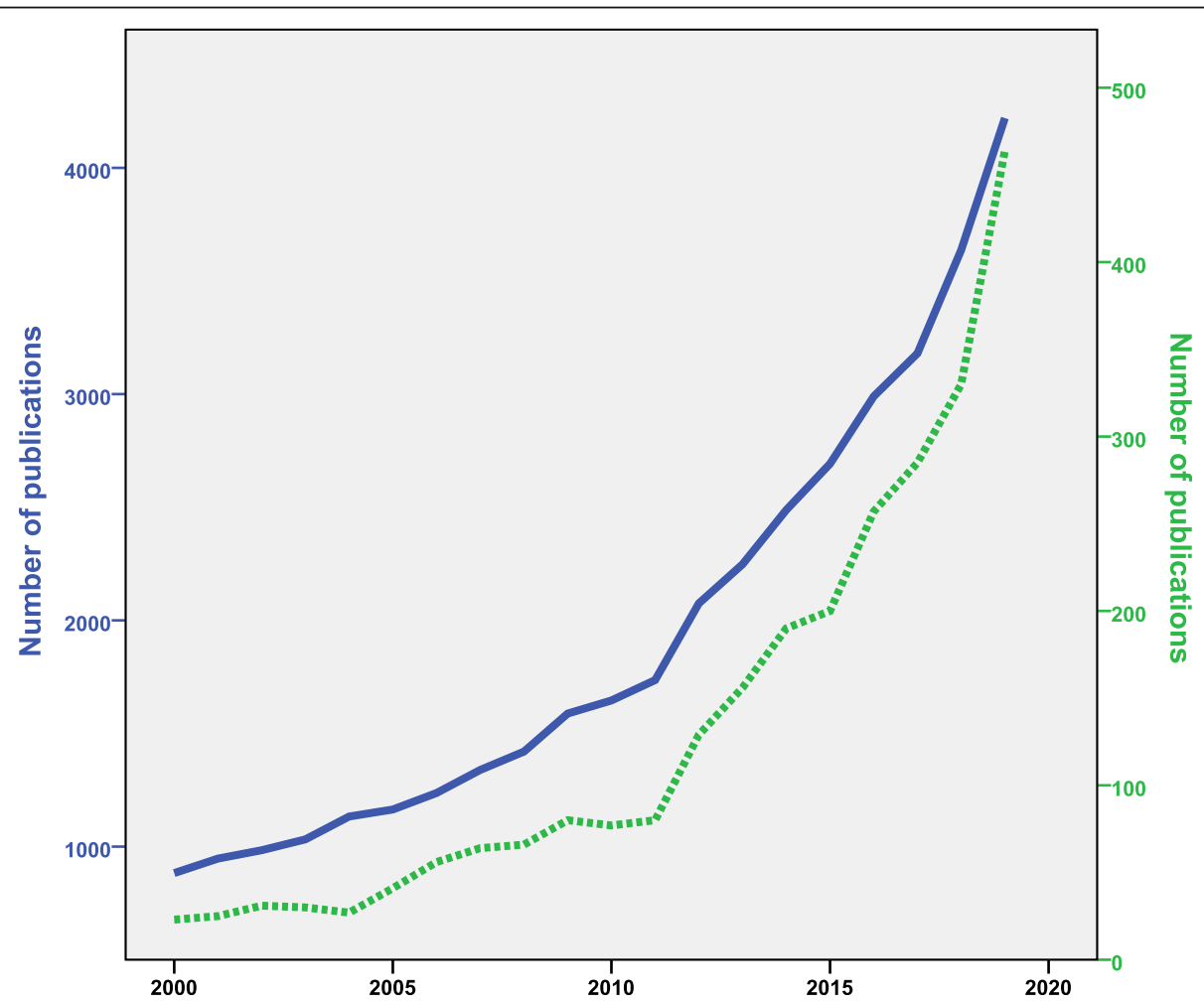

Fig. 1 Annual growth of publications on antimicrobial resistance in the environment. The dashed green line represents the annual growth of AMR in the environment while the blue line represents the annual growth of publications on AMR in general 


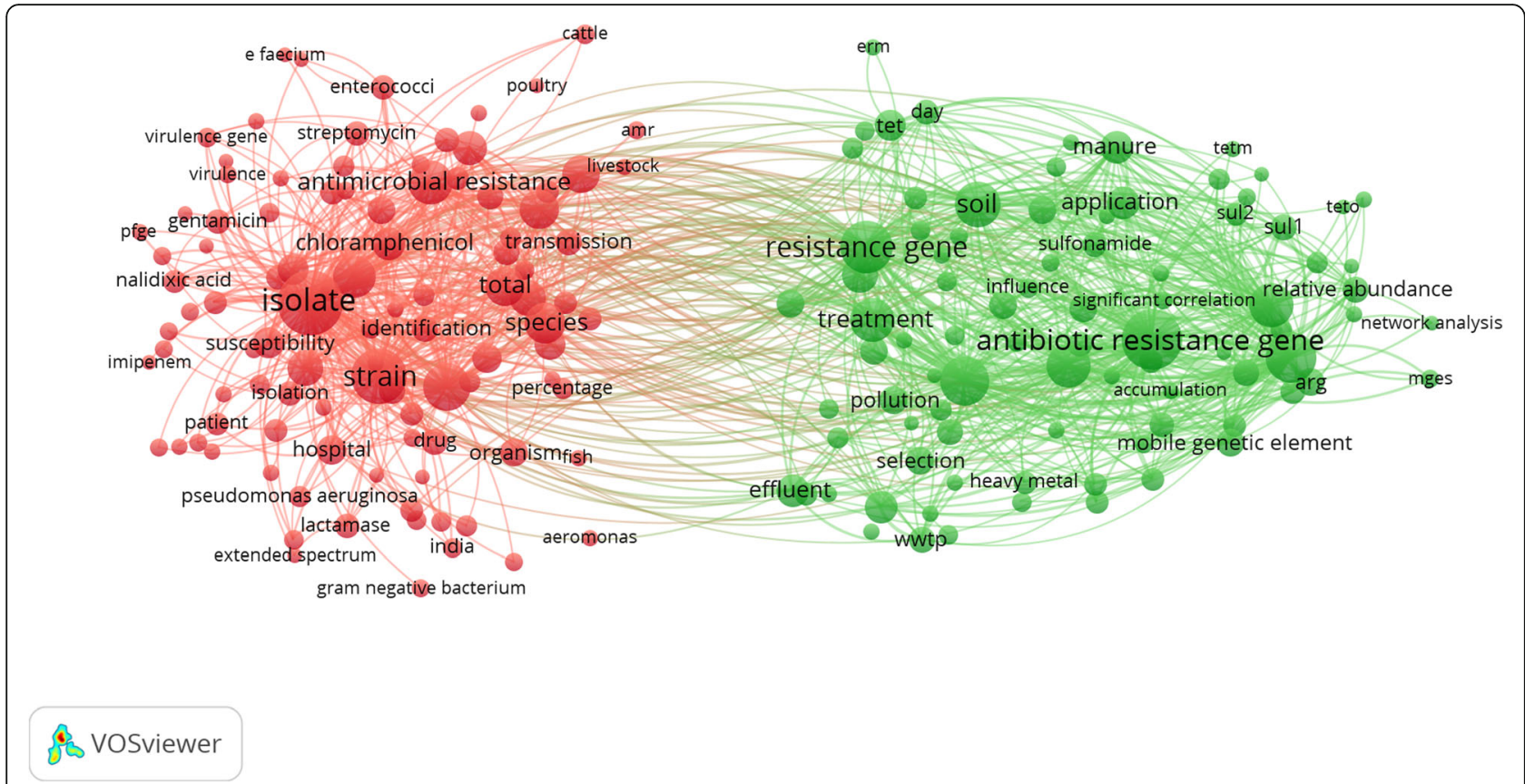

Fig. 2 Network visualization map of most frequent terms in titles/abstracts of the retrieved literature on AMR in the environment (2000-2019). The two clusters represent the major research themes in the retrieved literature

Enterococcus faecalis/faecium $(n=134)$, and Salmonella $(n=119)$.

\section{Geographic distribution of the retrieved documents}

Authors from the European region participated in 899 (34.4\%) of the retrieved literature. Authors from the region of the Americas participated in 756 (29.0\%) articles while authors from the Western Pacific region participated in $743(28.5 \%)$ articles. The least contribution was made by authors from the South-Eastern Asian region $(n=259 ; 9.9 \%)$, the Eastern Mediterranean region $(n=$ $179 ; 6.9 \%)$ and the African region $(n=151 ; 5.8 \%)$.

Table 1 Top ten frequent drug classes encountered in the retrieved documents (AMR in the environment) during the study period from 2000 to 2019

\begin{tabular}{lll}
\hline Rank & Drug class & $\begin{array}{l}\text { Occurrences (\%) } \\
\mathbf{N}=2611\end{array}$ \\
\hline 1 & Penicillin and Cephalosporines (B-Lactams) & $1152(44.1)$ \\
2 & Aminoglycosides & $1052(40.3)$ \\
3 & Tetracycline & $958(36.7)$ \\
4 & Quinolones/ Fluoroquinolones & $852(32.6)$ \\
5 & Folate antagonists & $831(31.8)$ \\
6 & Macrolids & $462(17.7)$ \\
7 & Chloramphenicol & $409(15.7)$ \\
8 & Carbapenems (B-Lactams) & $227(8.7)$ \\
9 & Glycopeptides (vancomycin,) & $222(8.5)$ \\
10 & Polypeptide (Colistin/Polymyxin) & $42(1.6)$ \\
\hline
\end{tabular}

AMR antimicrobial resistance

\section{Active countries}

Table 2 showed the top 10 active countries. China led with $598(22.9 \%)$ articles followed by the USA $(n=511$; $19.6 \%)$. The top 10 active countries contributed to 2082 articles (79.7\%). The top active countries included one in South America, two in Northern America, five in Europe, one in the Western Pacific region, and one in South-Eastern Asian region. When data were normalized by income and population size, India ranked first followed by China. Figure 3 compared the growth of publications from the USA and China. Publications from China started later than that from the USA. However, the productivity from China exceeded that from the USA in the last 4 years.

\section{International research collaboration}

Countries with a minimum contribution of 50 documents were visualized to assess international research collaboration among active countries (Fig. 4). For research collaboration, the strongest was between China and the USA (link strength $=58$ ) followed by that between the USA and Canada (link strength $=38$ ). The link strength was less than 10 for most countries indicative of inadequate international research collaboration.

\section{Citation analysis}

The retrieved documents received 75,331 citations, an average of 22 citations per document and an $h$-index of 122. Publications from China had the highest scientific 
Table 2 Top ten active countries in AMR in the environment research (2000-2019)

\begin{tabular}{llll}
\hline Rank & Country & $\begin{array}{l}\text { Frequency (\%) } \\
\boldsymbol{N}=2611\end{array}$ & Number of publications/ GDP (nominal) per capita (10 $\left.{ }^{-3}\right)^{*}$ \\
\hline 1 & China & $598(22.9)$ & 59.2 \\
2 & United States & $511(19.6)$ & 7.8 \\
3 & $196(7.5)$ & 89.1 \\
4 & India & $147(5.6)$ & 3.6 \\
5 & United Kingdom & $132(5.1)$ & 2.9 \\
6 & Canada & $129(4.9)$ & 2.8 \\
7 & Germany & $110(4.2)$ & 3.7 \\
8 & Spain & $101(3.9)$ & 11.5 \\
9 & Brazil & $90(3.4)$ & 3.9 \\
10 & Portugal & $68(2.6)$ & 1.6 \\
\hline
\end{tabular}

$\left({ }^{*}\right)$ Number of publications/GDP (nominal) per capita was calculated by dividing the number of publications by the GDP (nominal) per capita for each country. Data on GDP (nominal) per capita was obtained from the World Bank data $A M R$ antimicrobial resistance

impact followed by those from the USA as measured by normalized citations (Fig. 5).

\section{Active institutions}

The leading role of China in this field was reflected in the findings that four of the top 10 academic institutions/organizations were based in China. The top active institution was the Chinese Academy of Sciences $(n=177 ; 6.8 \%)$ followed by Agriculture et Agroalimentaire Canada $(n=$ 52; 3.2\%), and Ministry of Education China ( $n=44,1.7 \%)$. Other active institutions were listed in Table 3.

\section{Active journals}

The top 10 active journals are listed in Table 4 . The active journals published 689 (26.4\%). Science of The Total Environment journal was the most prolific journal with

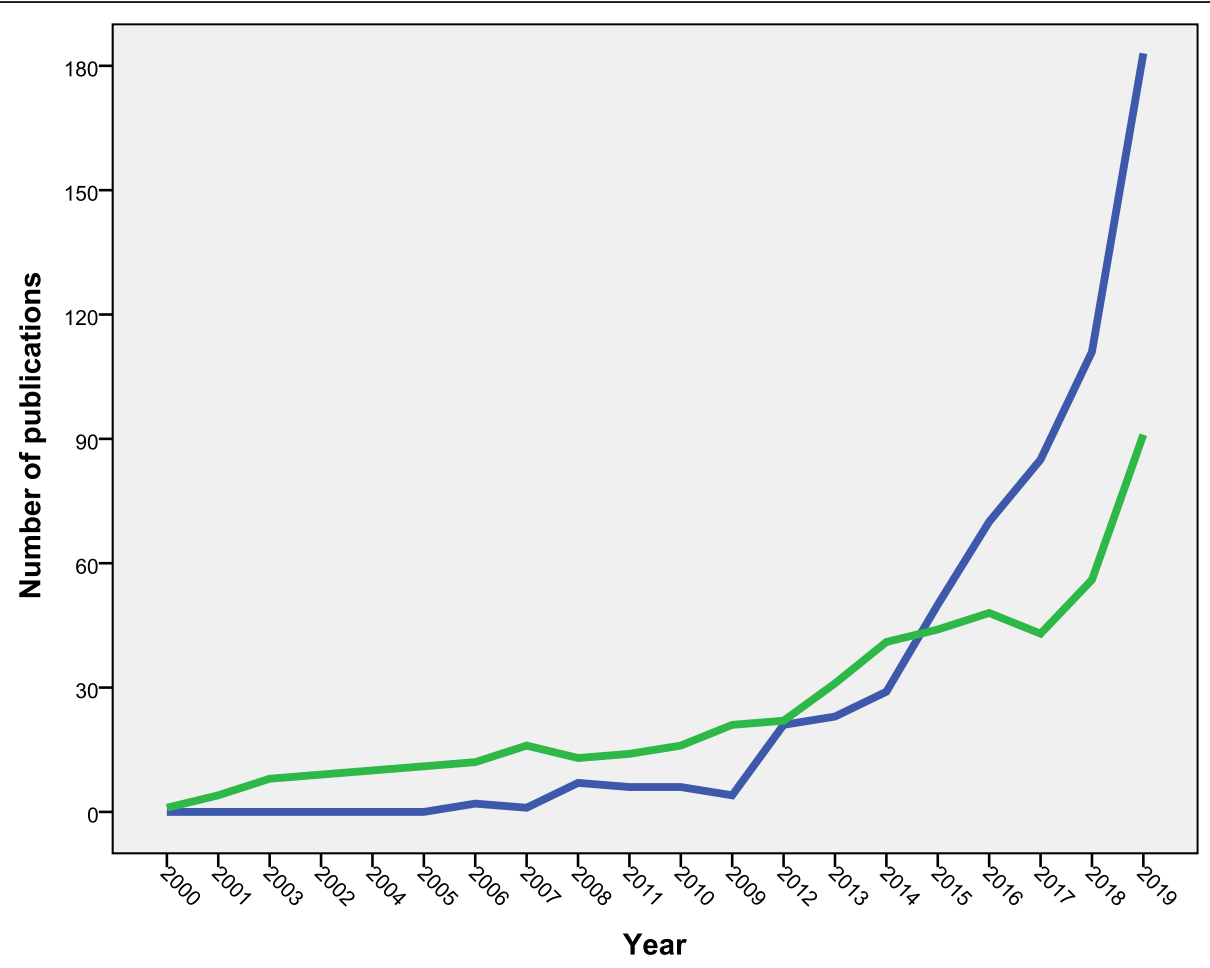

Fig. 3 Comparison of the annual growth of publications on antimicrobial resistance in the environment. The green line represents the annual growth of publications from the USA while blue line represents the annual growth of publications from China 


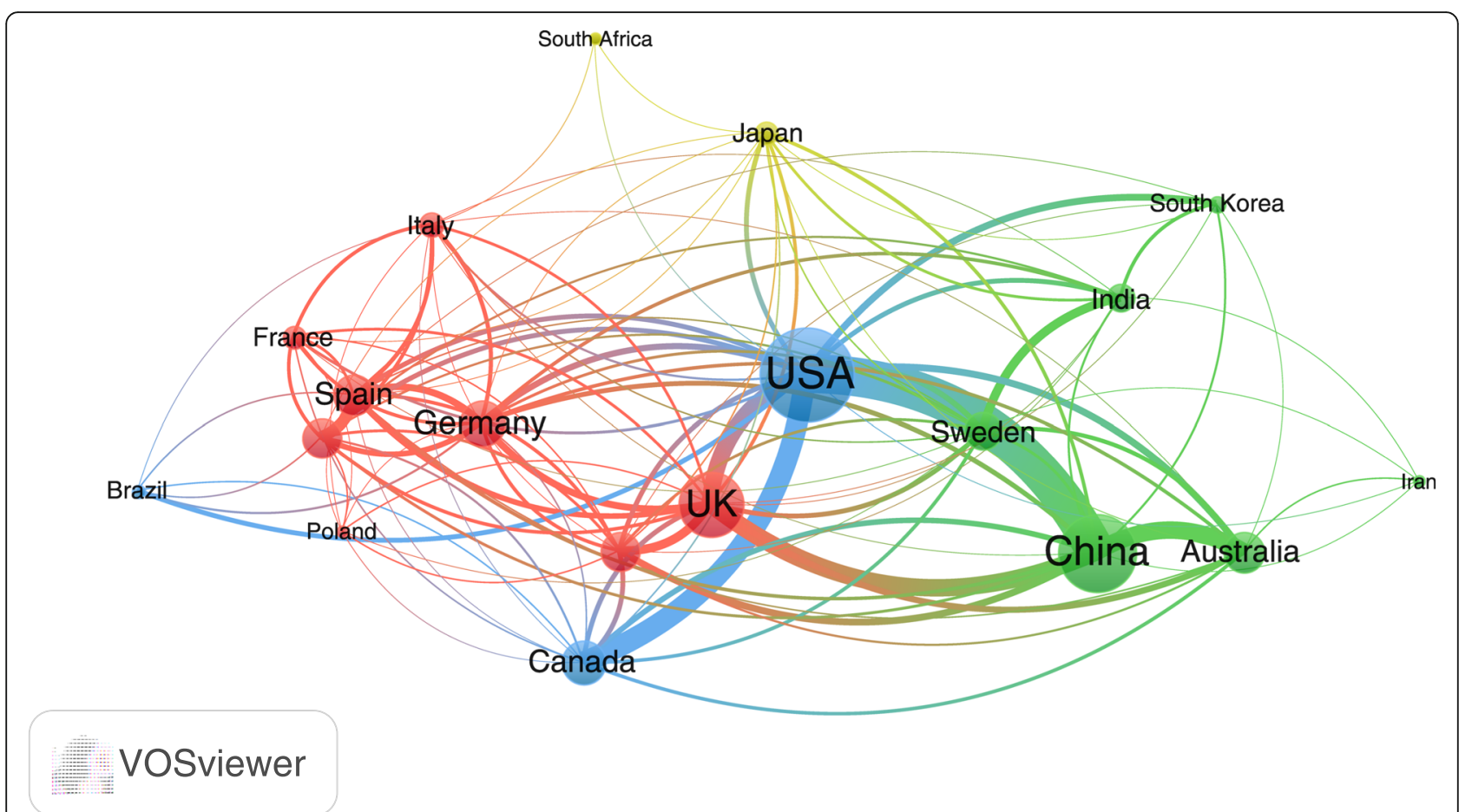

Fig. 4 Network visualization map of international research collaboration among countries with minimum research output of 50 documents on AMR in the environment. The thickness of the connecting lines represents the strength of research collaboration between any two countries. The connecting line between the USA and China represents the strongest research collaboration due to it thickness relative to other lines

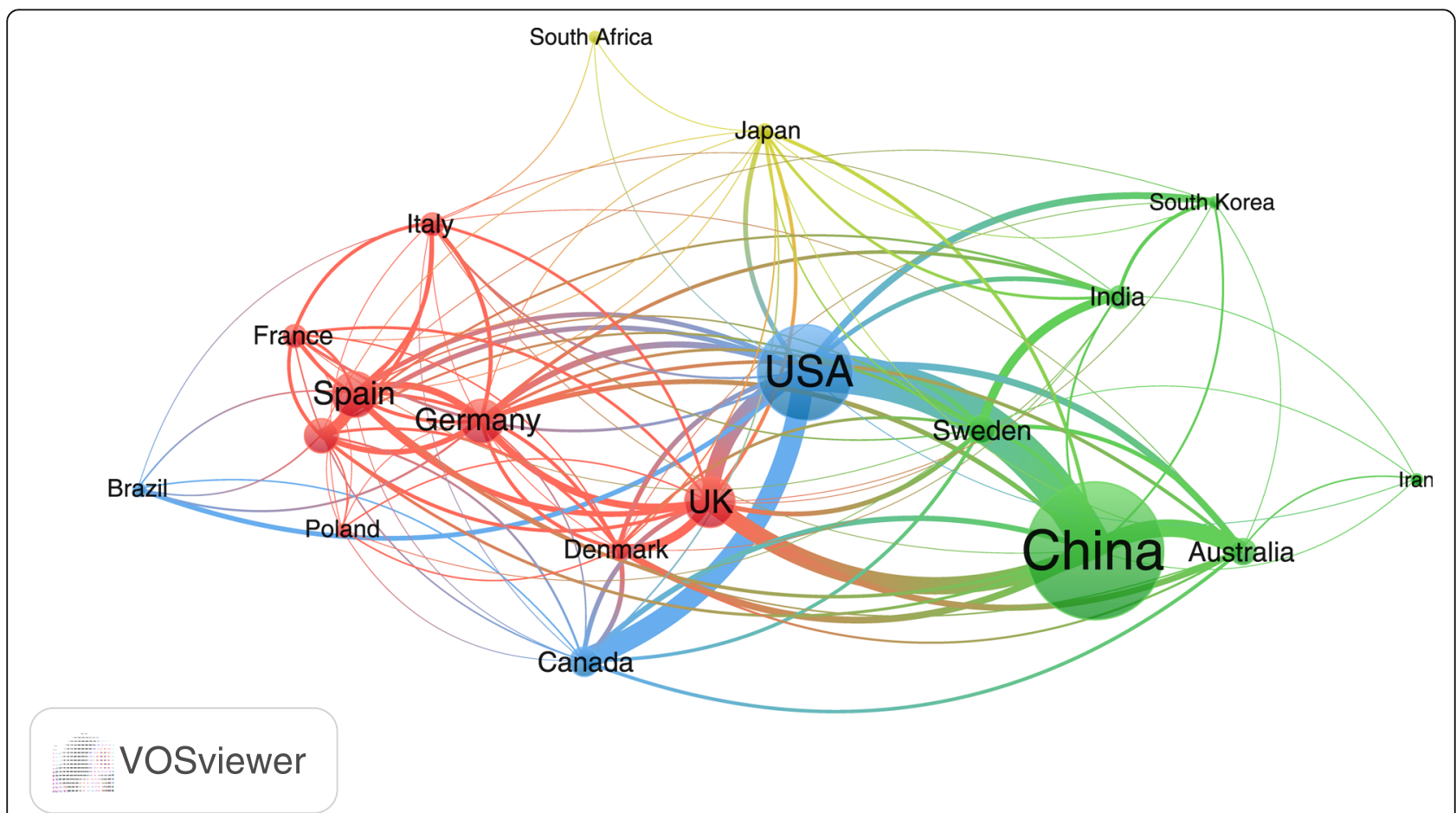

Fig. 5 Network visualization map of scientific impact of publications from countries with minimum research output of 50 documents. Publications from China have the highest scientific impact due to the size of the node representing China 
Table 3 List of top ten active institutions in AMR in the environment (2000-2019)

\begin{tabular}{llll}
\hline Rank $^{\text {a }}$ & institution & $\begin{array}{l}\text { Frequency } \\
(\%)\end{array}$ & Country \\
& & N=2611 & \\
\hline 1 & Chinese Academy of Sciences & $177(6.8)$ & China \\
2 & Agriculture et Agroalimentaire Canada & $52(2.0)$ & Canada \\
3 & Ministry of Education China & $44(1.7)$ & China \\
3 & Universidade Catolica Portuguesa, Porto & $44(1.7)$ & Portugal \\
5 & USDA Agricultural Research Service, & $41(1.6)$ & USA \\
& Washington DC & & \\
7 & Northwest A\&F University & $40(1.5)$ & China \\
8 & Tsinghua University & $38(1.5)$ & China \\
9 & Universidade do Porto & $32(1.2)$ & Portugal \\
10 & Zhejigang State University & $29(1.1)$ & USA \\
10 & The University of Hong Kong & $27(1.0)$ & China \\
& & $27(1.0)$ & Hong \\
& & & Kong
\end{tabular}

$A M R$ antimicrobial resistance

${ }^{a}$ Two equal institutions were given the same rank and one place in the ranking order is skipped

139 publications followed by Frontiers in Microbiology with 89 publications. The top 10 active journals included six journals in the field of environmental sciences, three in microbiology, one in environmental microbiology, and one miscellaneous journal. The Science of The Total Environment journal received the highest normalized citation per document. All journals in the top 10 list ranked by Scopus as Q1 and all of them were affiliated with countries in the top 10 list, mainly with the USA, the UK, and the Netherlands.

\section{Funding agencies}

Of the retrieved articles, 1973 (75.5\%) publications were funded projects. The National Natural Science
Foundation of China $(315 ; 12.1 \%)$ was the most active funding agency in this field.

\section{Discussion}

The current study aimed to assess the scientific literature on AMR in the environment. The contamination of the environment with antibiotic-resistant bacteria, antibiotic-resistant genes, and residues of antibiotics constitute a global public health challenge due to their associated risk to human health [35]. Both the WHO and European action plans to tackle AMR mentioned the environment and called for developing guidelines and standards to minimize environmental pollution with antibiotics from various facilities [36, 37]. The presence of resistant bacteria and bacterial resistant genes in the environment has an active role in the propagation of AMR [38].

The current study showed that literature on AMR in the environment is growing. The growth of the publications was enhanced by the increasing recognition of scientists and international organizations that protecting the environment is the responsibility of a wide and diverse group of stakeholders [39]. The current study clearly showed that the retrieved documents belonged to a wide range of subject areas including environment, pharmacology, microbiology, and medicine suggesting that authors from different scientific backgrounds being involved in publishing the retrieved documents. A bibliometric study on pharmaceuticals in the environment showed exponential growth of literature in this field which spans multidisciplinary subjects [40].

The current study indicated that China and the USA were leaders in this field. China is one of the world regions where gram-negative bacterial resistance is severe and threatening human and animal health [41]. The irrational use of antimicrobials and the unregulated use of

Table 4 Top ten active journals in AMR in the environment research (2000-2019)

\begin{tabular}{|c|c|c|c|c|}
\hline $\operatorname{Rank}^{a}$ & Country & $\begin{array}{l}\text { Frequency (\%) } \\
\boldsymbol{N}=2611\end{array}$ & Rank & Affiliation \\
\hline 1 & Science of The Total Environment & $139(5.3)$ & Q1 & Netherlands \\
\hline 2 & Frontiers in Microbiology & $82(3.1)$ & Q1 & Switzerland \\
\hline 3 & Applied and Environmental Microbiology & $73(2.8)$ & Q1 & USA \\
\hline 4 & Environmental Pollution & $69(2.6)$ & Q1 & UK \\
\hline 5 & Water Research & $64(2.5)$ & Q1 & Netherlands \\
\hline 6 & Environmental Science and Technology & $60(2.3)$ & Q1 & USA \\
\hline 7 & Environmental Science and Pollution Research & $55(2.1)$ & Q1 & Germany \\
\hline 7 & Plos One & $55(2.1)$ & Q1 & USA \\
\hline 9 & Environment International & $48(1.8)$ & Q1 & UK \\
\hline 10 & Journal of Applied Microbiology & $44(1.7)$ & Q1 & UK \\
\hline
\end{tabular}

Q1: first quartile (highest rank)

${ }^{\mathrm{a}}$ Two equal journals were given the same rank and one place in the ranking order is skipped 
antimicrobials in food-producing animals in China are the main driving factors for the AMR crisis in China [42, 43]. A recently published research paper indicated that India and China are hot spots of antimicrobial resistance in animals and that Brazil and Kenya are newly emerging hot spots [44]. In the current study, both China and India ranked first and third respectively in the number of publications concerning AMR in the environment. Authors from the United States, the UK, Canada, and Germany ranked second, fourth, fifth, and sixth respectively. This result is not surprising since these countries are leading the world in research, including medicine [23, 24, 45]. The current study showed that Brazil ranked 9th in research activity on AMR in the environment. This might be due to the overuse of antimicrobials in animal-producing food. A study expected an increase in global consumption of antimicrobials by $67 \%$ by 2030 and that consumption in Asia is projected to increase to 51,851 tons which represents $82 \%$ of global antimicrobial consumption in food animals in 2010 [46]. The authors of the paper reported that in 2010 China (23\%), the United States (13\%), Brazil (9\%), India (3\%), and Germany (3\%) had the largest share of global use while in 2030 China (30\%), the United States (10\%), Brazil (8\%), India (4\%), and Mexico (2\%) will have the largest share of antimicrobial use in animal food [46].

The current study indicated the presence of two major themes in the retrieved literature: antibiotic in environmental isolates and abundance of resistant bacterial genes in various environmental compartments. The current study indicated that at least nine different antibiotic drug classes were encountered in the retrieved literature. These antibiotics have been reported in various environmental compartments in various parts of the world [47-49]. The massive non-clinical use of antibiotics led to the presence of these antibiotics in large quantities in human-made environments such as sewage and wastewater treatment plants and marine environments [12, 13]. The presence of antibiotic residues in the environment triggers bacterial mutation favoring resistance due to selective pressure. Antibiotic-resistant genes are disseminated in the environment through a horizontal or vertical transfer with the potential of exchange between environmental and pathogenic bacteria [50]. Humans become exposed to these resistant pathogens by direct or indirect contact with the environment or animals.

In the current study, environment journals and water research journals were in the top 10 active list. A study showed that Chemosphere journal published the largest number of articles followed by the Science of the Total Environment journal while Water Research journal ranked the first in the category list of water resources and the second in the category of environmental / engineering [51]. In the current study, none of the journals in the top active list was in public health or general medicine. The majority of retrieved documents was in the subject area of environmental sciences followed by microbiology/immunology. The link between environment and human health is well established and the development of AMR in the environmental components should be considered a national and global public health priority [52].

The current study showed relatively high citations and $h$-index indicative of a large number of readers interested in the subject. The $h$-index of documents on AMR in the environment was higher than that reported for literature on strongyloidiasis [53], epidermal parasitic skin diseases [54], and AIDS-related stigma [54] but equal to that on carbapenem resistance [23]. The high $h$-index value even in the presence of limited international research collaboration is evidence of the importance of the topic itself rather than self-citations. The high number of citations was also enhanced by the involvement of highly influential journals in publishing documents in this field.

The current study is the first bibliometric study to study this topic and present detailed information on research trend and growth on this emerging topic. However, the fact that we used Scopus to retrieve relevant literature with the exclusion of grey literature and publications in un-indexed journals make the data uncomprehensive. The term environment is very broad. In the search strategy, we used the maximum known terms but not all possible ones. Third, the validation of the study was based on previously used validation method. However, a small percentage of error remains a possibility and might be reflected on the listing of active players in the field. This small percentage of error is due to the fact that not all retrieved studies can be assessed and confirmed for its relevance to the topic of the study.

\section{Conclusion}

Antimicrobial resistance is a global and multidimensional problem that needs a comprehensive, global, and "One Health" approach. In the current study, scientific literature on the AMR in the environment was assessed and analyzed. Literature in this field has witnessed a rapid and steep growth in the last decade. China and Chinese institutions played a leading role in this field. Two major themes dominated the literature on AMR and the environment: the presence of antibiotics in various environmental compartments and the abundance and dissemination of antibiotic-resistant genes in the environment. The literature in this field was mainly within environmental and microbiology subject areas. Information regarding AMR and the environment need to be obtained from all world regions including the Eastern 
Mediterranean and African regions. Pathogenic bacteria and resistant genes frequently encountered in the retrieved literature need to be considered in national and global policies and environmental technologies implemented.

\section{Supplementary information}

Supplementary information accompanies this paper at https://doi.org/10. 1186/s41256-020-00165-0.

\section{Additional file 1. \\ Additional file 2 \\ Additional file 3 .}

\section{Abbreviations}

AMR: Antimicrobial resistance; WHO: World Health Organization; USA: United States of America; UK: United Kingdom

Ethic approval and consent to participate

No approval is needed for this study.

\section{Code availability}

Not applicable.

\section{Authors' contributions}

WS and MA started the idea, designed the methodology; did the data analysis, graphics, and data interpretation; wrote and submitted the manuscript.

\section{Funding}

None.

\section{Availability of data and materials}

All data presented in this manuscript are available on Scopus database using the search query listed in the methodology section.

\section{Consent for publication}

Not applicable.

\section{Competing interests}

The authors declare that they have no competing interests.

\section{Author details}

${ }^{1}$ Department of Physiology, Pharmacology/Toxicology, College of Medicine and Health Sciences, An-Najah National University, Nablus, Palestine. ${ }^{2}$ Business Faculty, Al-Balqa Applied University, Amman, Jordan.

Received: 6 April 2020 Accepted: 6 July 2020

Published online: 03 August 2020

\section{References}

1. World Health Organization. Ten threats to global health in 2019. 2019. Available from https://www.who.int/emergencies/ten-threats-to-globalhealth-in-2019.

2. Walsh TR. A one-health approach to antimicrobial resistance. Nat Microbiol. 2018;3(8):854-5.

3. Robinson TP, Bu D, Carrique-Mas J, Fèvre EM, Gilbert M, Grace D, Hay SI, Jiwakanon J, Kakkar M, Kariuki S. Antibiotic resistance is the quintessential one health issue. Trans R Soc Trop Med Hyg. 2016:110(7):377-80.

4. Thakur S, Gray GC. The mandate for a global "one health" approach to antimicrobial resistance surveillance. Am J Trop Med Hygiene. 2019;100(2): 227.

5. Centers for Disease Control and Prevention. One health basics. https://www. cdc.gov/onehealth/basics/index.html. Accessed 10 Apr 2020.

6. United Nations. Political declaration of the high-level meeting of the General Assembly on antimicrobial resistance; 2016.
7. Gostin LO, Friedman EA. The sustainable development goals: one-health in the world's development agenda. JAMA. 2015;314(24):2621-2.

8. Gebreyes WA, Dupouy-Camet J, Newport MJ, Oliveira CJ, Schlesinger LS, Saif YM, Kariuki S, Saif LJ, Saville W, Wittum T. The global one health paradigm: challenges and opportunities for tackling infectious diseases at the human, animal, and environment interface in low-resource settings. PLoS Negl Trop Dis. 2014;8(11):e3257.

9. Godfroid J, Al Dahouk S, Pappas G, Roth F, Matope G, Muma J, Marcotty T, Pfeiffer D, Skjerve E. A "one health" surveillance and control of brucellosis in developing countries: moving away from improvisation. Comp Immunol Microbiol Infect Dis. 2013;36(3):241-8.

10. Essack SY. Environment: the neglected component of the one health triad. Lancet Planet Health. 2018;2(6):e238-9.

11. Holmes AH, Moore LS, Sundsfjord A, Steinbakk M, Regmi S, Karkey A, Guerin PJ, Piddock LJ. Understanding the mechanisms and drivers of antimicrobial resistance. Lancet. 2016;387(10014):176-87.

12. Rizzo L, Manaia C, Merlin C, Schwartz T, Dagot C, Ploy MC, Michael I, FattaKassinos D. Urban wastewater treatment plants as hotspots for antibiotic resistant bacteria and genes spread into the environment: a review. Sci Total Environ. 2013;447:345-60.

13. Boy-Roura M, Mas-Pla J, Petrovic M, Gros M, Soler D, Brusi D, Mencio A. Towards the understanding of antibiotic occurrence and transport in groundwater: findings from the Baix Fluvia alluvial aquifer (NE Catalonia, Spain). Sci Total Environ. 2018:612:1387-406.

14. Rabinowitz P, Conti L. Links among human health, animal health, and ecosystem health. Annu Rev Public Health. 2013:34:189-204.

15. Da Costa PM, Loureiro L, Matos AJ. Transfer of multidrug-resistant bacteria between intermingled ecological niches: the interface between humans, animals and the environment. Int J Environ Res Public Health. 2013;10(1): 278-94.

16. Berendonk TU, Manaia CM, Merlin C, Fatta-Kassinos D, Cytryn E, Walsh F, Bürgmann H, Sørum H, Norström M, Pons M-N. Tackling antibiotic resistance: the environmental framework. Nat Rev Microbiol. 2015;13(5):3107.

17. Wallin JA. Bibliometric methods: pitfalls and possibilities. Basic Clin Pharmacol Toxicol. 2005;97(5):261-75.

18. Van Raan AF. Advances in bibliometric analysis: research performance assessment and science mapping. In: Bibliometrics Use and Abuse in the Review of Research Performance; 2014. p. 17-28.

19. Peters MD, Godfrey CM, Khalil H, Mclnerney P, Parker D, Soares CB. Guidance for conducting systematic scoping reviews. Int J Evid Based Healthc. 2015;13(3):141-6.

20. Møller A, Myles P. What makes a good systematic review and meta-analysis? $\mathrm{Br} J$ Anaesth. 2016;117(4):428-30.

21. Grant MJ, Booth A. A typology of reviews: an analysis of 14 review types and associated methodologies. Health Inf Libr J. 2009;26(2):91-108.

22. Levac D, Colquhoun H, O'Brien KK. Scoping studies: advancing the methodology. Implement Sci. 2010;5(1):69.

23. Sweileh WM, Shraim NY, Al-Jabi SW, Sawalha AF, AbuTaha AS, Zyoud SH. Bibliometric analysis of global scientific research on carbapenem resistance (1986-2015). Ann Clin Microbiol Antimicrob. 2016;15(1):56.

24. Sweileh WM, Al-Jabi SW, Sawalha AF, AbuTaha AS, Zyoud SH. Bibliometric analysis of publications on Campylobacter: (2000-2015). J Health Popul Nutr. 2016;35(1):39.

25. Sweileh WM. Global research trends of World Health Organization's top eight emerging pathogens. Glob Health. 2017;13(1):9.

26. Sweileh WM. Bibliometric analysis of literature on female genital mutilation: (1930 - 2015). Reprod Health. 2016;13(1):130.

27. Sweileh WM, Al-Jabi SW, Zyoud SH, Sawalha AF, Abu-Taha AS. Global research output in antimicrobial resistance among uropathogens: a bibliometric analysis (2002-2016). J Global Antimicrob Resist. 2018;13:104-14

28. Falagas ME, Pitsouni El, Malietzis GA, Pappas G. Comparison of PubMed, Scopus, web of science, and Google scholar: strengths and weaknesses. FASEB J. 2008:22(2):338-42.

29. Radhouani H, Silva N, Poeta P, Torres C, Correia S, Igrejas G. Potential impact of antimicrobial resistance in wildlife, environment and human health. Front Microbiol. 2014;5:23.

30. Williams MR, Stedtfeld RD, Guo X, Hashsham SA. Antimicrobial resistance in the environment. Water Environ Res. 2016;88(10):1951-67.

31. Topp E, Larsson DJ, Miller DN, Van den Eede C, Virta MP. Antimicrobial resistance and the environment: assessment of advances, gaps and 
recommendations for agriculture, aquaculture and pharmaceutical manufacturing. FEMS Microbiol Ecol. 2018;94(3):fix185.

32. Van Eck NJ, Waltman L. Text mining and visualization using VOSviewer. In: Centre for Science and Technology Studies. The Netherlands: Leiden University; 2011.

33. Van Eck NJ, Waltman L: VOSviewer manual. Leiden: Univeristeit Leiden 2013, $1(1): 1-53$.

34. Hirsch JE. An index to quantify an individual's scientific research output. Proc Natl Acad Sci. 2005;102(46):16569-72.

35. Singh R, Singh AP, Kumar S, Giri BS, Kim KH. Antibiotic resistance in major rivers in the world: a systematic review on occurrence, emergence, and management strategies. J Clean Prod. 2019;234:1484-505.

36. World Health Organization (WHO): Global action plan on antimicrobial resistance. 2015.

37. Paphitou NI. Antimicrobial resistance: action to combat the rising microbial challenges. Int J Antimicrob Agents. 2013;42:S25-8.

38. Singer AC, Shaw H, Rhodes V, Hart A. Review of antimicrobial resistance in the environment and its relevance to environmental regulators. Front Microbiol. 2016;7:1728.

39. Food and Agricultural Organization of the United Nations (FAO): Antimicrobial Resistance in the Environment; 2018.

40. Daughton CG. Pharmaceuticals and the environment (PiE): evolution and impact of the published literature revealed by bibliometric analysis. Sci Total Environ. 2016:562:391-426.

41. Qu J, Huang Y, Lv X. Crisis of antimicrobial resistance in China: now and the future. Front Microbiol. 2019:10:2240.

42. Wang M. Antimicrobial resistance in China: challenges and actions. Clin Infect Dis. 2018:67(suppl_2):S127.

43. Hu F, Zhu D, Wang F, Wang M. Current Status and Trends of Antibacterial Resistance in China. Clin Infect Dis. 2018;67(suppl_2):S128-s134.

44. Van Boeckel TP, Pires J, Silvester R, Zhao C, Song J, Criscuolo NG, Gilbert M, Bonhoeffer S, Laxminarayan R. Global trends in antimicrobial resistance in animals in low- and middle-income countries. Science. 2019;365(6459): eaaw1944.

45. Sweileh WM. Global research output on HIV/AIDS-related medication adherence from 1980 to 2017. BMC Health Serv Res. 2018;18(1):765.

46. Van Boeckel TP, Brower C, Gilbert M, Grenfell BT, Levin SA, Robinson TP, Teillant A, Laxminarayan R. Global trends in antimicrobial use in food animals. Proc Natl Acad Sci U S A. 2015;112(18):5649-54.

47. Hanna N, Sun P, Sun Q, Li X, Yang X, Ji X, Zou H, Ottoson J, Nilsson LE, Berglund $\mathrm{B}$, et al. Presence of antibiotic residues in various environmental compartments of Shandong province in eastern China: its potential for resistance development and ecological and human risk. Environ Int. 2018; 114:131-42.

48. Chen D, Liu S, Zhang M, Li S, Wang J. Comparison of the occurrence of antibiotic residues in two rural ponds: implication for ecopharmacovigilance. Environ Monit Assess. 2018;190(9):539.

49. Shi Y, Liu J, Zhuo L, Yan X, Cai F, Luo W, Ren M, Liu Q Yu Y. Antibiotics in wastewater from multiple sources and surface water of the Yangtze River in Chongqing in China. Environ Monit Assess. 2020;192(3):159.

50. Ashbolt NJ, Amezquita A, Backhaus T, Borriello P, Brandt KK, Collignon P, Coors A, Finley R, Gaze WH, Heberer T, et al. Human health risk assessment (HHRA) for environmental development and transfer of antibiotic resistance. Environ Health Perspect. 2013;121(9):993-1001.

51. Zheng CL, Cotner JB, Sato C, Li G, Xu YY. Global development of the studies focused on antibiotics in aquatic systems from 1945 to 2017. Environ Sci Pollut Res Int. 2018;25(22):22023-34.

52. Corvalán CF, Kjellstrom T, Smith KR. Health, environment and sustainable development: identifying links and indicators to promote action. Epidemiology. 1999;10(5):656.

53. Sweileh WM. A bibliometric analysis of human strongyloidiasis research (1968 to 2017). Trop Dis Travel Med Vaccines. 2019;5:24.

54. Sweileh WM. Global output of research on epidermal parasitic skin diseases from 1967 to 2017. Infect Dis Poverty. 2018;7(1):74.

Ready to submit your research? Choose BMC and benefit from:

- fast, convenient online submission

- thorough peer review by experienced researchers in your field

- rapid publication on acceptance

- support for research data, including large and complex data types

- gold Open Access which fosters wider collaboration and increased citations

- maximum visibility for your research: over $100 \mathrm{M}$ website views per year

At BMC, research is always in progress.

Learn more biomedcentral.com/submissions 